Article

\title{
A Simple-to-Implement Fault Diagnosis Method for Open Switch Fault in Wind System PMSG Drives without Threshold Setting
}

\author{
Tan Yanghong ${ }^{1}$, Zhang Haixia ${ }^{1, *}$ and Zhou Ye ${ }^{2}$ \\ 1 College of electrical and information engineering, Hunan University, Changsha 410082, China; \\ tanyho@hnu.edu.cn \\ 2 NARI Group Corporation/State Grid Electric Power Research Institute, Nanjing 210003, China; \\ zhouye3@sgepri.sgcc.com.cn \\ * Correspondence: haixia521119@163.com; Tel.: +86-188-5102-0957
}

Received: 30 July 2018; Accepted: 31 August 2018; Published: 26 September 2018

\begin{abstract}
The conversion system is a major contributor to failure rates. These faults lead to time and cost consuming. Fault diagnosis capabilities pay as a solver to achieve a steady system. This paper presents a full analysis of permanent magnet synchronous generator wind system (PMSGWS) and proposes a special RMS voltage-based fault diagnosis method. The full analysis presents a comprehensive knowledge of faulty behaviors especially under arm current flowing or cutting off. Due to enough knowledge of faulty behaviors, the implementation of the detection method without threshold setting is contributed by the special RMS voltage. Its sample period is set longer than the time of the maximum pulse width ratio (MPR) and shorter than the fault show time of lower tube voltage. Due to this, the detection speed and robustness are achieved. By these simple settings for the fault diagnosis method, the faulty switch is detected in less than $1 / 4$ of the period. Simulation and experimental results confirm the validity and feasibility of the new proposed fault detection method.
\end{abstract}

Keywords: permanent magnet synchronous generator (PMSG); fault diagnosis; faulty operation analysis; pulse-width modulation (PWM); current analysis; RMS; diagnosis of synchronous machines

\section{Introduction}

Due to high efficiency and wide flux-weakening capability, a permanent magnet synchronous generator (PMSG) has been widely employed in many industrial applications such as a wind energy system (WS). These applications have always demanded service continuity, reliability, and availability. In practice, although PMSG as one of the mature technologies in WS has been widely adopted, its accidents due to some factors such as friction [1,2], high temperature [3], and an operation process, have inevitably occurred [4,5]. Various faults may have occurred in rotor bar [6,7], engine [8], bearing $[9,10]$, wind turbine gearboxes [11], and more. Faulty events may have damaged electrical energy, threatened the safety of the power system, and even harmed human lives and environments [4].

Currently, the diagnostic technique topic is very large $[12,13]$. In view of the fault parts, various approaches have been proposed to monitor and detect many kinds of faults. For instance, the methods in References [1,2] have been proposed for detecting the faults in the brake system. In Reference [6], motor current signals analysis by the tooth-fast fourier transform (FFT) has been used to detect both incipient and consolidated broken rotor bars conditions. In addition, for the detection of the half broken rotor bar fault, the other method known as the motor square current MUSIC analysis has been presented in Reference [7]. The manuscript [8] has focused on wall conveyor engines diagnosis. On the basis of these three models (signal correlation, extreme vibration, and RMS intensity), monitoring RMS and extreme values has served as a leading indicator for early detection of faults [9]. Bearing faults has 
been diagnosed by the extended park vector approach [11]. The open-circuit fault (OCF) causes that the phase winding has been disconnected from or one leg of the inverter bridge has failed have been researched in Reference [14].

The fact that electronics faults in WS has accounted to about $1 \%$ of the total cost only, which was indicated in Reference [4]. Power converter failures have been generally categorized into two types of faulty, short-circuit faults (SCF) together with OCF. When an SCF has occurred, drive systems have been immediately stopped or transformed into OCF by the emergency control schedule for alleviating or isolating the fatal damage by SCF. While OCFs are associated with slow responses and less danger, it is still connected with gird for the economy and safety [15]. Yet, the potential safety problems could not have been ignored by the public [4]. Many articles have focused on reliability issues of power electronics monitoring methods $[4,5,16]$. Generally, these fault diagnosis methods are achieved by the output current or voltage signals such as current-based methods or voltage-based methods [17].

Current-based methods often have depended on arm current. In order to simplify the application and improve diagnostic speed, the normalized way using three-phase currents has been developed for multiple OCF in insulated gate bipolar transistors (IGBTs) for the power inverter in electric vehicles [18]. By the measurement of the output inverter currents, a fuzzy technique has detected intermittent loss of firing pulses in the inverter power switches to diagnosis [19]. The manuscript [20] has presented an OCF diagnostic method of inverters in closed-loop controlled PMSG drive systems based on the current residual vector (CRV). For detection and discrimination of OCF in a five-leg voltage source inverter feeding a five-phase biharmonic PMSG, the investigation into real-time faults diagnosis has been conducted [21]. The method by using adaptive thresholds has been proposed for multiple IGBTs OCF and current sensor faults detection [22]. The method proposed in Reference [23] was achieved by analyzing and combining the information provided with the line current shapes in the $\alpha-\beta$ frame and their normalized mean values under both healthy and faulty operating conditions. These methods have had a major drawback, which involves sensitivity to transients. The current signals have been load dependent [24]. For instance, literature [25] has indicated that current measurement noises and inverter dead-time harmonics have resulted in the distortion on DQ currents, which limits fault detection performance [26].

Aiming to dissolve this drawback, the data-driven methods have been used to detect faults. For instance, the Bayesian network in Reference [24] has been adopted for diagnosis. On the basis of FFT, the relative principle component analysis (RPCA) and the support vector machine (SVM), which is a fault diagnosis method, has been proposed for detecting OCFs in an H-bridge multilevel inverter [27]. By analyzing the output currents of normal and fault states, a fault diagnosis algorithm has been designed and achieved by a multistate data processing (MSDP) block, a subsection fluctuation analysis (SSFA) block, and the artificial neural network (ANN) block [28]. The paper [29] attempted to develop a novel method of training the ANN for a fault diagnosis technique of the OCF in converters of the PMSGWS. However, these data-driven methods take a long time to record data and to train the network [30].

Voltage-based methods have decreased sensitivity to transients and are achieved with a shorter detection time in comparison with that of current-based methods [25] even though additional sensors or other hardware devices have been required. On the basis of the output line-to-line voltage model, a novel diagnostic technique developed and proposed in Reference [31] has allowed a fast detection time and a good performance. A voltage-based detection method realized by the principle component analysis and the multiclass relevance vector machine (PCA-m RVM) has designed for the cascaded H-bridge multilevel inverter system (CHMLIS) [32]. On the aim of avoiding additional sensors, the three-phase voltages calculated by the DC link voltage and switching times contributed toward detection in Reference [25]. The calculated amount increased and was very time-consuming. Observer-based approaches have also been addressed in References [33-35]. In Reference [34], both IGBTs OCF and current sensor faults in three-phase PMSG drives have been distinguished. 
The proposed diagnosis method in Reference [35] has been successful in the detection of multiple OCF. However, an adaptive threshold has been necessary for these observer-based approaches.

In practice, each switch is composed of a power switch and a parallel freewheel diode (PFD). The power switch is more sensitive than the PFD. References $[15,16]$ have indicated the fact that an OCF may have occurred in the power switch only $[15,16]$. This kind of OCF is named the open switch fault (OSF). The OSFs have remained undetected and led to potential secondary faults [17,30]. After an OSF occurred in a back-to-back converter using NPC topology for wind turbine systems [36] or a three-phase pulse-width modulating (PWM) voltage source rectifier (VSR) system [37], these converters have been open to a two-way traffic for faulty current. In addition, it has two different characteristics during the zero-crossing and non-zero-crossing section. In fact, this phenomenon also has produced in the event of OSF in PMSG drives, which we verify in the next sections. If the faulty currents have gone through the converter unidirectionally, the faulty characteristics of current, harmonic, temperature distribution and more have been shown clearly [38]. However, to a bi-directional faulty current, the distortions have been found difficult due to the small residuals [37]. The performance of the method achieved by residuals may have been reduced [39]. Therefore, for distinguishing between the OSF and the normal commutation operation, the threshold has been necessary, according to Reference [37]. The dissatisfaction with reliability issues of power electronic voltage-based monitoring methods has been exposed [5].

This paper analyzes the faulty behaviors of PMSG drives in WS and proposes a new OSF detection and faulty switch identification algorithm. This proposed fault diagnosis scheme is implemented on the basis of the faulty behavior analysis. In consideration of fault-mode behavior during the zero-crossing and non-zero-crossing faulty current section, the detection method without a threshold setting comes from the feature of lower tube voltage. Due to the criteria in a lower tube voltage, a special RMS voltage is obtained in a certain period. The detection time and the robustness are also achieved by this certain period. All authors of this paper are devoted to the simple implementation of the detection method. Section 1 investigates OSF in PMSG drives of WS. The effects on current and voltage are also discussed in this section by presenting the detail fault-mode behavior. In Section 2, the identification method for OSF is proposed. The simulation and experimental results are presented in order to evaluate the fault diagnosis performance in Section 3. Lastly, the concluding remarks are provided in Section 4.

\section{Investigation into Faults of PMSG Drives}

The PMSGWS consists of three main parts: wind turbine (WT), PMSG, and the conversion system. The grid side converter (GSC), the motor side converter (MSC), and the DC-Link capacitor compose the wind conversion chain. It joints PMSG and the grid, isolates PMSG from the grid, reduces the damage from the PMSG, and keeps the power balance.

\subsection{Faulty Circuit Analysis of the PMSG Drives}

Certain simplifying assumptions are made at first. The switches of the converter are ideal whose power loss and resistance are equal to 0 . The back trapezoidal EMFs (back electromotive force) of generator $e_{k s}(k=a, b, c)$, phase stator resistance $R_{k s}(k=a, b, c)$, and phase stator inductance $L_{k s}(k=a, b, c)$ are connected in series at each phase to arrive at the PMSG drives model. Each converter consists of three arms. Each switch is composed of a power switch and a PFD. Figure 1 gives an equivalent circuit of PMSG drives, which is constrained by $e_{k s}$ and the arm current $i_{k}^{s}(k=a, b, c)$ seen in Equation (1).

$$
\left\{\begin{array}{l}
e_{a s}+e_{b s}+e_{c s}=0 \\
i_{a}^{s}+i_{b}^{s}+i_{c}^{s}=0
\end{array}\right.
$$




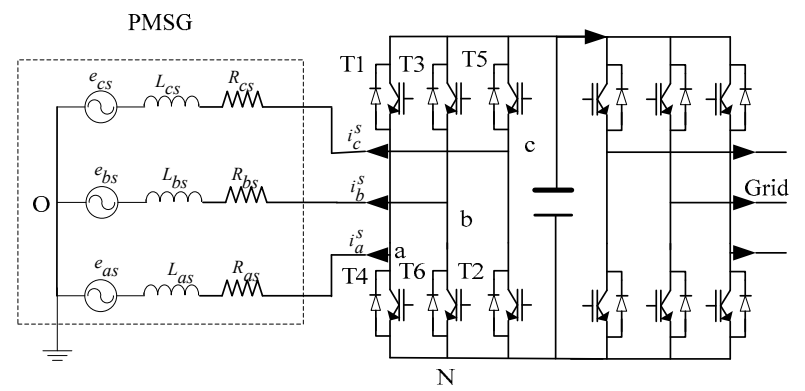

Figure 1. Equivalent circuit of PMSG drives.

With reference to Figure 1, the dynamics of PMSG connected to inverters is governed by the following nonlinear differential equations.

$$
\left\{\begin{array}{l}
L_{a s} d i_{a}^{s} / \mathrm{dt}+R_{a s} i_{a}^{s}=u_{a 0}-e_{a s} \\
L_{b s} d i_{b}^{s} / \mathrm{dt}+R_{b s} i_{b}^{s}=u_{b 0}-e_{b s} \\
L_{c s} d i_{c}^{s} / \mathrm{dt}+R_{c s} i_{c}^{s}=u_{c 0}-e_{c s}
\end{array}\right.
$$

Let switching function decide by $s_{a}, s_{b}$, and $s_{c}$. For example, $s_{a}=1 \Rightarrow T_{1}=O N, s_{a}=0 \Rightarrow$ $T_{4}=O N$. Arm currents $i_{k}^{s}$ flowing into the windings are defined as positive. Current direction and switching signal determine the lower tube voltages $u_{k N}(k=a, b, c)$ that can be expressed by the equation below.

$$
u_{k N}=s_{k} u_{d c} \quad(k=a, b, c)
$$

where $u_{d c}$ is the dc-link voltage. $u_{k N}$ plus the N-to-neutral voltage $u_{N 0}$ is the winding-to-neutral voltages $u_{k 0}(k=a, b, c)$. Adding three sub-equations of Equation (2), we can obtain the mathematic expressions of $u_{N 0}$ and $u_{k 0}$.

$$
\begin{gathered}
u_{N 0}=-\left(s_{a}+s_{b}+s_{c}\right) u_{d c} / 3 \\
\left\{\begin{array}{l}
u_{a 0}=\left(2 s_{a}-s_{b}-s_{c}\right) u_{d c} / 3 \\
u_{b 0}=\left(2 s_{b}-s_{a}-s_{c}\right) u_{d c} / 3 \\
u_{c 0}=\left(2 s_{c}-s_{b}-s_{a}\right) u_{d c} / 3
\end{array}\right.
\end{gathered}
$$

If the power switch fault by the gate driver failure results in OCF in MSC, the PFD of the faulty power switch still connects with MSC, builds the current path, and contributes to PMSG current flowing. Assuming that T1 fails to turn on or off, we only control T4. For the sake of the zero-crossing condition of the faulty current, the analysis of faulty behaviors is divided into the two following parts.

\subsection{1. (A) The Non-Zero-Crossing Section of the Faulty Current $\left(i_{a}^{s} \neq \neq 0\right)$}

In detail, if $s_{a}=0$, the lower switch T4 is on $u_{a N}$ is identically equal to zero. When $s_{a}=1, u_{a N}$ and $i_{a}^{s}$ are found based on the following rules. $e_{b s}$ and $u_{d c}$ affect the conduction of the antiparallel diode VD4. Once forward conduction current flows through VD4, $u_{a N}=0$ and $i_{a}^{s}>0$. If not, $i_{a}^{s}$ flows from the generator and charges the DC-Link capacitor $u_{a N}=u_{d c}$ and $i_{a}^{s}<0$. In other words, if $u_{a N}$ is proper, $i_{a}^{s}$ can flow through VD1 or VD4. So $i_{b}^{s}$ can flow though bilaterally. Now, the T1 fault results in the following relation.

$$
\left\{\begin{array}{ll}
u_{a N}=0 & i_{a}^{s}>0 \\
u_{a N}=u_{d c} & i_{a}^{s}<0
\end{array} \text { and } s_{a}=1\right.
$$

Substituting Equation (6) into Equation (2), we get the phase-A equations below.

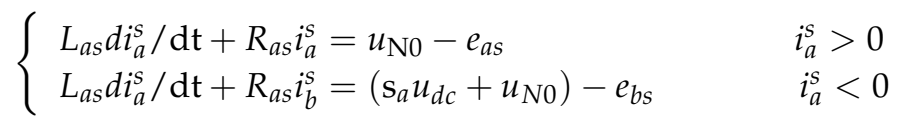


As is clear from Equation (7), the arm current can flow through bilaterally. The form of Equation (7) indicates that the distortions of arm current are nonlinear.

\subsection{2. (B) The Zero-Crossing Section of Faulty Current $\left(i_{a}^{\mathcal{s}}=0\right)$}

The threshold voltage of VD1 or VD4 is assumed as $u_{D} \cdot e_{a s}$ is decided by the wind turbine. When $i_{a}^{s}=0, u_{a 0}$ is equal to $e_{a s}$ in view of Figure 1. $e_{a s}$ and $u_{N 0}$ affect the conduction of the antiparallel diode VD1 or VD4. If $e_{a s}-u_{N 0}>u_{D}$, VD1 conducts. As a consequence, $u_{a N}=u_{d c}-u_{D}$ and $u_{N 0}=e_{a s}-u_{d c}-u_{D}$; if $u_{N 0}-e_{a s}<u_{D}$, VD4 conducts. After this, $u_{a N}=-u_{D}$ and $u_{N 0}=e_{a s}-u_{D}$. We also analyzed the condition where VD1 and VD4 cannot conduct. The switches on phase B and C are still controlled by $s_{b}$ and $s_{c}$. According to Reference [40], three-phase voltages are constrained by the equation below.

$$
u_{a 0}+u_{b 0}+u_{c 0}=0
$$

Taking $u_{a 0}=e_{a s}$ and changing Equation (3) into Equation (8), we can obtain the following formula.

$$
u_{N 0}=-\left[e_{a s}+\left(s_{b}+s_{c}\right) u_{d c}\right] / 2
$$

This time $u_{a N}=\left[3 e_{a s}+\left(s_{b}+s_{c}\right) u_{d c}\right] / 2$, which is different from the conditions related to VD1 or VD4 conducting.

\subsection{Distortion of Arm Current}

\subsubsection{The Control Strategy}

The control strategy for MSC generally includes the following two closed loops: speed loop and flux loop [41]. The complete block diagram is shown in Figure 2.

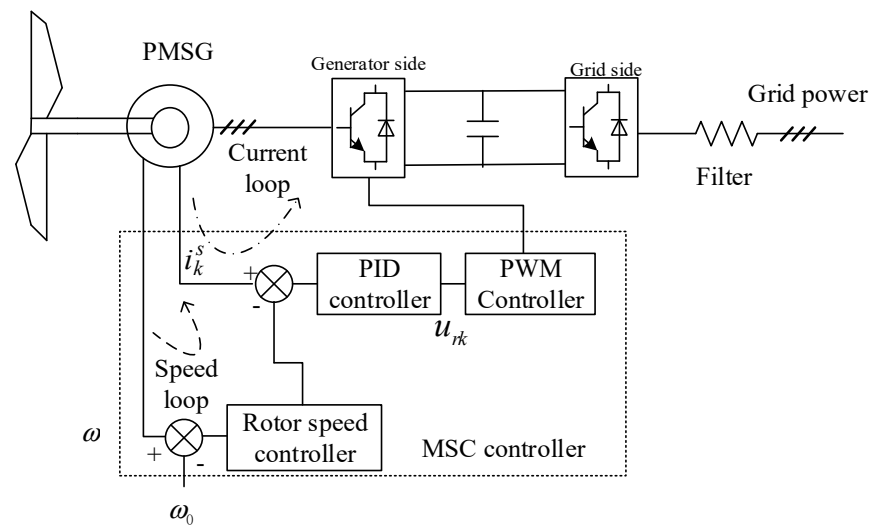

Figure 2. The control strategy for MSC.

In view of Figure 2, we express PWM control signals $u_{r k}$ through the equation below.

$$
u_{r k}=g\left(i_{k}^{s}, \omega\right)
$$

where $\omega$ is the actual rotor speed. In Equation (10), $i_{k}^{s}$ takes part in flux regulation. We assume that the wind speed is fixed. Then, $\omega$ is a constant. $i_{k}^{s}$ change when a T1 fault occurs. In fact, once an OSF happens, $i_{k}^{s}$ should change. As a consequence, $u_{r a}, u_{r b}$, and $u_{r c}$ are also altered due to Equation (10). Switching signals are confined by $u_{r a}, u_{r b}$, and $u_{r c}$, which is shown in Figure 2.

In general, the PWM control is achieved by a comparing process described in Figure 3. In this process, the reference value $u_{0}$ is always stable after leaving the factory. 

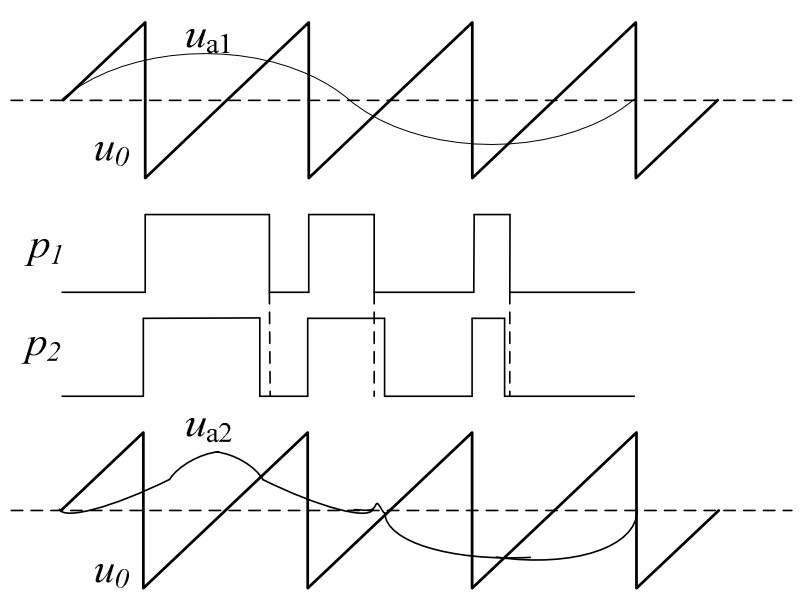

Figure 3. The control strategy for PWM.

It is assumed $u_{a 1}$ is deformed into $u_{a 2}$ after T1 fault occurrence. This assumption is built on the basis of the experiments and simulations in Section 2.2.2. Comparing $u_{a 1}$ and $u_{a 2}$ with $u_{0}$, we obtain different PWM signals as $P 1$ and $P 2$. Certain deductions can be made regarding that $P 1$ and $P 2$ are different. In an actual system, the frequency of $u_{0}$ is up to several thousand Hz. More errors between $P 1$ and $P 2$ would appear. Therefore, a strong coupling relationship between switching signals and arm current exists.

\subsubsection{The Dynamics of Arm Current}

Experiments and simulations are conducted to analyze the dynamics of the current. The experimental devices are shown in Figure 4. The main parameters of PMSG drives are given in Table 1.

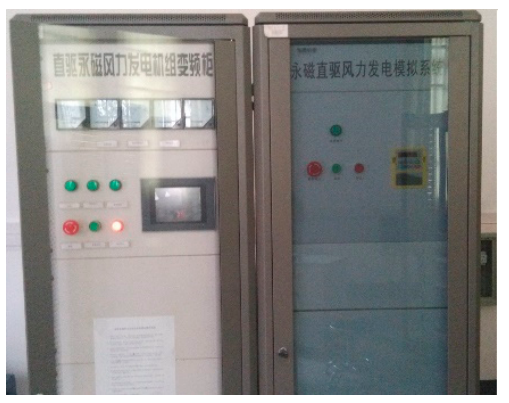

(a)

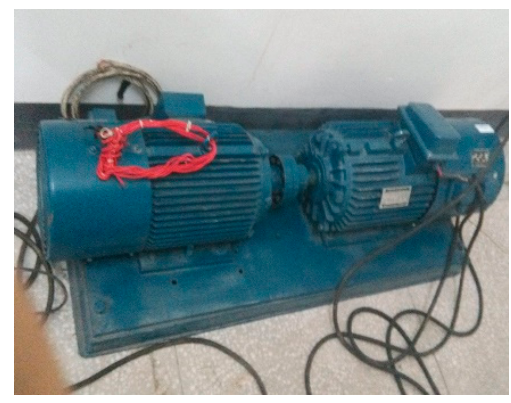

(b)

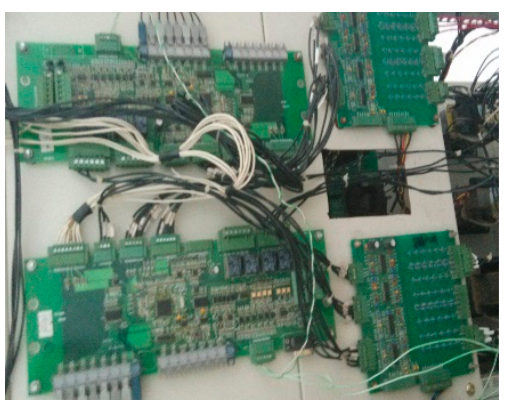

(c)

Figure 4. Experiment devices: (a) control panel; (b) generator; (c) the back-to-back converter control circuit.

Table 1. System parameters of experiments.

\begin{tabular}{ccccc}
\hline Device & \multicolumn{2}{c}{ Parameters } & Device & Parameters \\
\hline & rated power & $2.2 \mathrm{~kW}$ & DC-link capacitance & $1000 \mathrm{uF}$ \\
& rated voltage & $0.38 \mathrm{kV}$ & Grid equivalent inductance & $2 \mathrm{mH}$ \\
generator & rated frequency & $50 \mathrm{~Hz}$ & Rotational inertia of the generator & $0.0032 \mathrm{~kg} \cdot \mathrm{m}^{2}$ \\
& resistance & 0.86 & & \\
& inductance & $11.3 \mathrm{mH}$ & & \\
& voltage coefficient & $0.62 \mathrm{kv}$ & & \\
\hline
\end{tabular}


With parameters including a reference speed of $1200 \mathrm{r} / \mathrm{min}$ together with a load torque equal to $60 \%$ of the rated torque, experiments are conducted under two different conditions that are of a normal operation termed the T1 fault. T1 is the upper switch of MSC in phase A. For leading to OSF, the switching signal of T1 is forced to zero. The dynamic responses of $i_{k}^{s}$ are shown in Figure 5a,b. All curves of $i_{k}^{s}$ are bidirectional. Their envelopes are trigonometric functions with three similar elements. All distortions are hard to express by mathematical equations. Therefore, we believe the distortions of arm current are nonlinear.

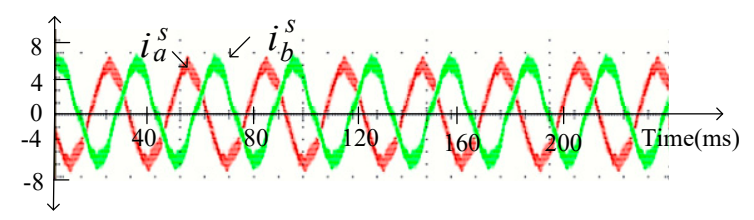

(a)

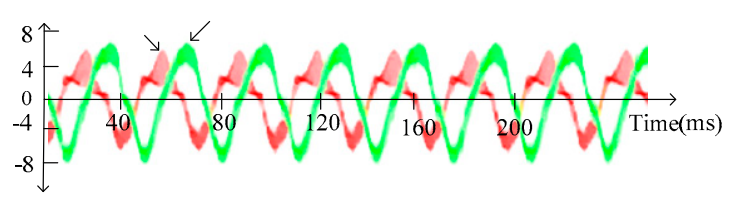

(b)

Figure 5. Experimental results regarding the time-domain waveforms of arm currents: (a) The normal operating condition; (b) the operating conditions at the time of the T1 fault.

The model simulations of PMSG drives are carried out by using PSCAD software. The model of PMSGWS is shown in Figure 6. The main system parameters of simulations are given in Table 2. $\mathrm{T} 1$ and T4 are the top and lower switches in phase A, respectively. Setting wind speed at $10.5 \mathrm{~m} / \mathrm{s}$, we simulate the model. Its dynamic responses of $i_{k}^{s}$ are plotted in Figure 7.

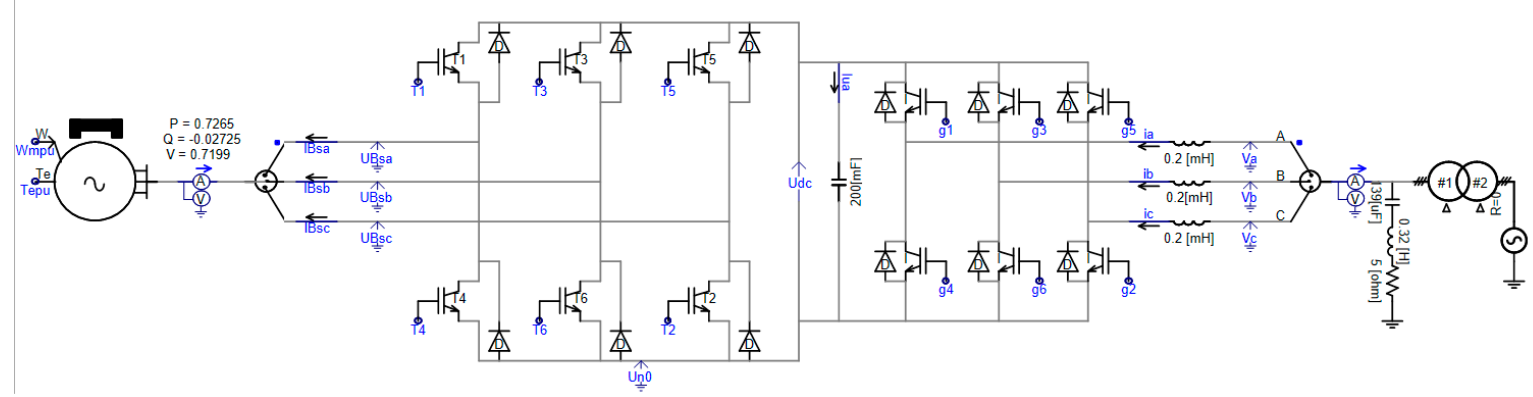

Figure 6. The model of PMSG drives.

Table 2. System parameters of simulations.

\begin{tabular}{ccccc}
\hline Device & \multicolumn{2}{c}{ Parameters } & Device & Parameters \\
\hline & rated power & $1.58 \mathrm{MVA}$ & DC-link capacitance & $200 \mathrm{mF}$ \\
& rated voltage & $0.69 \mathrm{KV}$ & Grid equivalent inductance & $0.2 \mathrm{mH}$ \\
generator & rated frequency & $50 \mathrm{HZ}$ & Rotational inertia of the generator & $2 \mathrm{pu}$ \\
& resistance & $0.017 \mathrm{pu}$ & & \\
& inductance & $0.064 \mathrm{pu}$ & & \\
& voltage coefficient & $1500 \mathrm{~V}$ & & \\
\hline
\end{tabular}




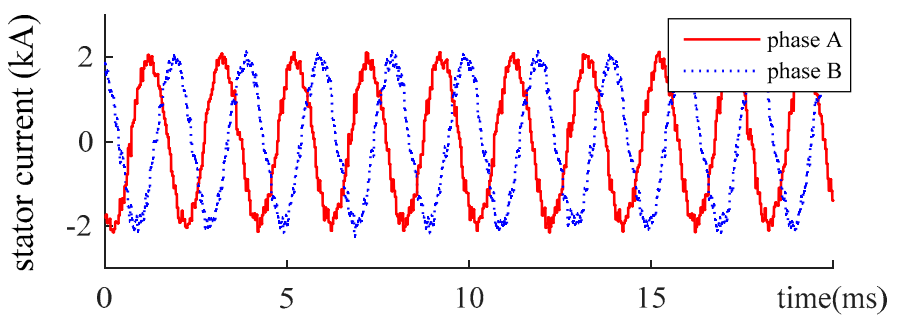

(a)

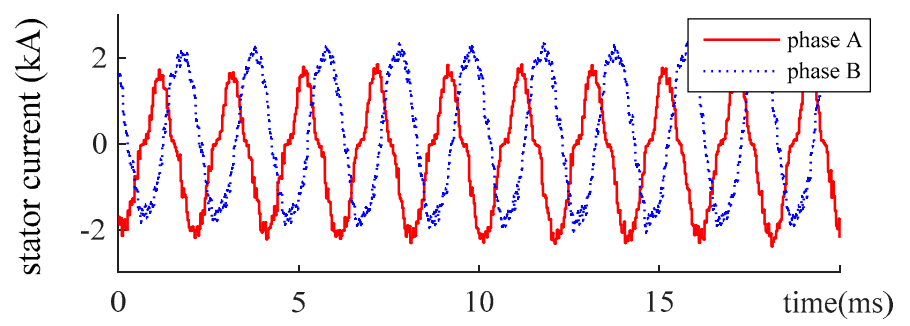

(b)

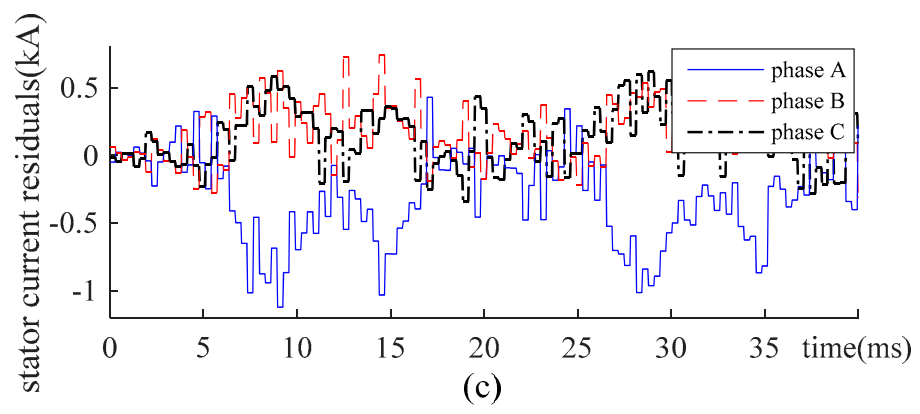

Figure 7. Simulation results regarding arm currents: (a) The normal operating condition; (b) the operating condition at the time of the T1 fault; (c) The arm current residuals in the event of the T1 fault.

In Figure $7 \mathrm{a}, \mathrm{b}$, all $i_{k}^{s}$ are bidirectional. The envelopes of curves are trigonometric functions. The two curves in Figure $7 \mathrm{~b}$ are obtained in the event of the T1 fault. The currents distort nonlinearly. Similar characteristics are reflected by both simulations and experiments. These similar characteristics also prove the simulation model is effective and available.

For analyzing dynamics of arm current, we also obtain the arm current residuals as shown in Figure 7c. In Figure 7c, three-phases residuals are generally not equal to 0 . Therefore, $i_{k}^{s}$ are distorted most of the time. All these curves are hard to express by mathematical functions. The distortions of $i_{k}^{s}$ are nonlinear. All results demonstrate the dynamic faulty behaviors in the event of the T1 fault. The distortions of $i_{k}^{s}$ are nonlinear.

\subsection{Distortion of Voltages}

\subsubsection{The Lower Tube Voltage}

Taking the T1 fault as an example, we study the responses of the lower tube voltage. Table 3 gives the responses of $u_{a N}$ during the T1 fault. 
Table 3. The values of $u_{a N}$.

\begin{tabular}{|c|c|c|c|c|c|c|c|c|c|}
\hline \multirow{2}{*}{ Faulty Switch } & \multirow{2}{*}{$\begin{array}{l}\text { Current } \\
\text { Direction }\end{array}$} & \multicolumn{8}{|c|}{$\left(s_{a} s_{b} s_{c}\right)$} \\
\hline & & 000 & 001 & 010 & 011 & 100 & 101 & 110 & 111 \\
\hline \multirow{3}{*}{$\mathrm{T} 1$} & $i_{a}^{s}>0$ & 0 & 0 & 0 & 0 & 0 & 0 & 0 & 0 \\
\hline & $i_{a}^{s}<0$ & 0 & 0 & 0 & 0 & & & & \\
\hline & $i_{a}^{s}=0$ & \multicolumn{8}{|c|}{$\begin{array}{l}\text { If VD1 conducts, } u_{a N}=u_{d c}-u_{D} \text {. If VD4 conducts, } u_{a N}=-u_{D} \text {. If both } \\
\text { VD1 and VD4 cannot conduct, } u_{a N}=\left[3 e_{a s}+\left(s_{b}+s_{c}\right) u_{d c}\right] / 2\end{array}$} \\
\hline No faulty switch & both & 0 & 0 & 0 & 0 & & & & \\
\hline
\end{tabular}

Let us now check all the values in Table 3. When OSF occurs in the upper switch and the arm current is positive, the lower tube voltages of faulty phase are equal to 0 . In other words, the lower tube voltages are not equal to DC-link voltage anymore when the faulty arm current is positive. When $i_{a}^{s}=0 . u_{a N}$ is obtained along with the various values that are unequal to 0 and $u_{d c}$. These criteria are a very helpful key for the OSF detection problem, which is summarized in Table 3. For the convenience of expression in the next sections, we call these periods $u_{a N}$, which are kept at 0 during the fault show time. The rest of the fundamental period is named the fault blank time.

\subsubsection{The Winding-to-Neutral Voltage}

We know $u_{k 0}$ in the normal condition as Equation (5). In this section, the mathematical expressions of $u_{k 0}$ in the event of the T1 fault are analyzed. At first, we analyze the condition regarding $i_{a}^{s} \neq 0$. Take Equation (6) into Equation (8) and calculate $u_{b N}, u_{c N}$ by using Equation (3). Now we can obtain the formula below.

$$
\begin{cases}u_{N 0}=-\left(s_{b}+s_{c}\right) u_{d c} / 3 & i_{a}^{s}>0 \\ u_{N 0}=-\left(s_{a}+s_{b}+s_{c}\right) u_{d c} / 3 & i_{a}^{s}<0\end{cases}
$$

Because the assumption that switches of the converter are ideal is made at the beginning of this section, we consider $u_{D}$ as 0 . During $i_{a}^{s}=0, u_{a 0}=e_{a s}$. The values of $u_{a N}$ are listed in Table 3 . We can obtain the following equations.

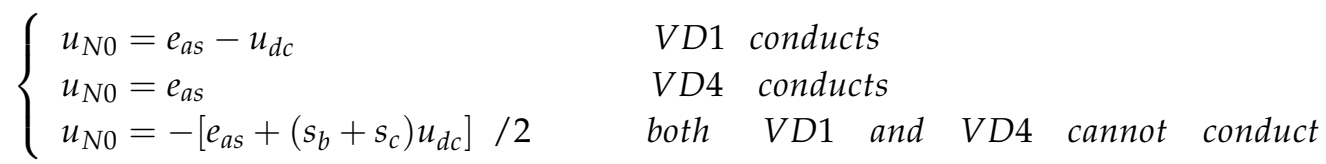

$u_{k N}$ plus $u_{N 0}$ is $u_{k 0}$. In view of $i_{a}^{s}$, we can express $u_{k 0}$ below.

$$
\begin{gathered}
\qquad \begin{cases}u_{a 0}=-\left(s_{b}+s_{c}\right) u_{d c} / 3 & i_{a}^{s}>0 \\
u_{a 0}=\left(2 s_{a}-s_{b}-s_{c}\right) u_{d c} / 3 & i_{a}^{s}<0 \\
u_{a 0}=e_{a s} & i_{a}^{s}=0\end{cases} \\
\begin{cases}u_{b 0}=\left(2 s_{b}-s_{c}\right) u_{d c} / 3 & i_{a}^{s}>0 \\
u_{b 0}=\left(2 s_{b}-s_{a}-s_{c}\right) u_{d c} / 3 & i_{a}^{s}<0 \\
u_{b 0}=s_{b} u_{d c}+e_{a s} & i_{a}^{s}=0 \text { and VD1 conducts } \\
u_{b 0}=\left(s_{b}-1\right) u_{d c}+e_{a s} & \text { and VD4 conducts } \\
u_{b 0}=\left[-e_{a s}+\left(s_{b}-s_{c}\right) u_{d c}\right] / 2 & i_{a}^{s}=0 \text { and both VD1 and VD4 cannot conduct }\end{cases}
\end{gathered}
$$




$$
\begin{cases}u_{c 0}=\left(2 s_{c}-s_{b}\right) u_{d c} / 3 & i_{a}^{s}>0 \\ u_{c 0}=\left(2 s_{c}-s_{a}-s_{b}\right) u_{d c} / 3 & i_{a}^{s}<0 \\ u_{c 0}=s_{c} u_{d c}+e_{a s} & i_{a}^{s}=0 \text { and VD1 conducts } \\ u_{c 0}=\left(s_{c}-1\right) u_{d c}+e_{a s} & i_{a}^{s}=0 \text { and VD4 conducts } \\ u_{c 0}=\left[-e_{a s}+\left(s_{c}-s_{b}\right) u_{d c}\right] / 2 & i_{a}^{s}=0 \text { and both VD1 and VD4 cannot conduct }\end{cases}
$$

Besides the condition of $i_{a}^{s}=0, u_{k 0}$ are decided by $s_{k}$ and $u_{d c}$. It is well known that $s_{k}$ are logical variables. Therefore, $u_{k 0}$ would be discrete most of the time. $u_{a 0}$ are less than 0 during $i_{a}^{s}>0$ according to Equation (13). As listed in Equations (13)-(15), the values of $u_{k 0}$ are affected by $e_{a s}, s_{b}$, and $s_{c} . u_{k 0}$ get various values, for example, $-2 u_{d c} / 3,0,2 u_{d c} / 3,-u_{d c} / 3, u_{d c} / 3, u_{d c}+e_{a s}, e_{a s}$ and so on. Owing to the randomness of wind, the values of $e_{a s}$ are in a wide range. Due to this, we can deduce that $u_{k 0}$ possibly has more than 10 values. The values of $u_{k 0}$ are more than that of $u_{k N}$. Therefore, the distortions of $u_{k N}$ are easier to discover than that of $u_{k 0}$.

Looking back at all these investigations, we can list the following conclusions. First, the bidirectional arm current can flow through MSC in the event of OSF. The relationship between arm current and the switching signal is strong coupling. The distortions of arm current are nonlinear. In addition, when an OSF occurs, the fault show time of $u_{k N}$ comes out. The values of $u_{k 0}$ have a wide range. The distortions of $u_{k N}$ are easier to discover than that of $u_{k 0}$.

\section{The Proposed Open-Circuit Fault Diagnosis}

Too many factors are influenced on arm current in the event of an OSF in MSC. The wide range of values $u_{k 0}$ is too complex to detect. Fortunately, we find the criteria that is summarized in Table 3 as a very helpful key for the OSF detection problem. The fault diagnostic formula is studied below.

\subsection{Method of Fault Diagnose}

Figure 8 illustrates the proposed fault diagnosis algorithm for detecting the OSF condition and identifying the faulty switch. This algorithm contains three steps including measurement, comparison, and classification.

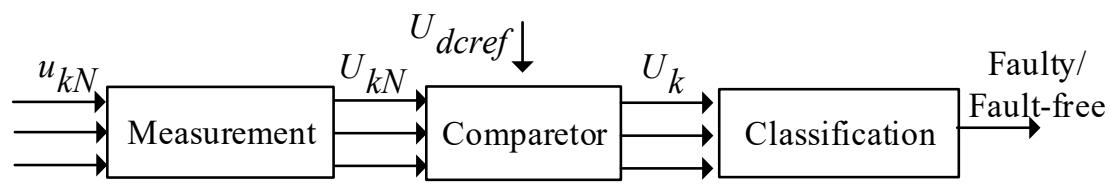

Figure 8. Block diagram of the fault detection method.

Measurement is the most important process of the proposed fault diagnosis algorithm. After this process, we can obtain a special RMS voltage $U_{k N}$, which is the key for deciding fault localization variables. In addition, the details of this process are explained in Section 2.3.

The second step is a comparison between $U_{k N}$ and $u_{d c}$. Let DC-Link reference voltage $U_{d c r e f}$ equal $u_{d c}$. By this step, fault localization variables $U_{k}$ appear. If $U_{k}$ is equal to 0 or 1 , the fault show time would appear. It can also deduce that an OSF happens. We collect the values of $U_{k}$ after all possible single switch faults occurred in MSC as Table 4 lists.

Table 4. The fault location rules for the faulty switch.

\begin{tabular}{|c|c|c|c|c|c|c|c|}
\hline$U_{a}$ & $U_{b}$ & $U_{c}$ & Faulty Switch & $U_{a}$ & $U_{b}$ & $U_{c}$ & Faulty Switch \\
\hline 1 & & & $\mathrm{~T} 4$ & & 1 & & T6 \\
\hline 0 & & & $\mathrm{~T} 1$ & & 0 & & T3 \\
\hline & & 1 & $\mathrm{~T} 2$ & & & 0 & T5 \\
\hline
\end{tabular}


Classification is designed as the last step of the detection method. Table 4 shows different faulty switches come with different fault localization variables $U_{k}$. So the faulty switch can be detected according to these variables.

In this fault diagnosis method, the setting of threshold is unnecessary. Only the values in the fault show time are considered. The misjudgment during the faulty current cutting off would should be avoided. In the detection process, we only monitor the lower tube voltage and sample with a certain period. The implementation of the detection method for OSF in MSC is very simple. The fault feature is obtained from the lower tube voltage directly in which it is easier to distinguish faulty switches in comparison to residuals. Surely, $T_{S}$ influences on the detection speed and the cost of the detection method.

\subsection{Fault Detection Time}

PWM frequency is several hundred times bigger than grid frequency and is not proper for sampling because of the high cost of the sensors. To shorten this cost, we choose other frequencies to sample. As the above proposed method, $T_{S}$ is the one we use to monitor lower tube voltage. $T_{S}$ is the major parts of fault detection time. The shorter detection time, the less the period $T_{s}$. The other problem is choosing $T_{S}$. which may affect the reliability of the detection method. In detail, if $T_{S}$ is too large, the fault show time may not be detected and if it is too small, the possibility of false detection increases. Therefore, this part introduces many problems such as how to choose the proper period $T_{s}$, how long the fault detection time takes, and so on.

\section{(A) Choosing the Proper Period $T_{s}$}

Several methods such as intelligent methods and empirical selection are effective and available to obtain $T_{s}$. Considering the merit and disadvantage of experimental conditions and each method, one of the most reliable choice methods known as the empirical selection is employed in this paper.

$T_{S}$ is bigger than the time of the maximum pulse width ratio (MPR) and shorter than the fault show time, according to Section 2.1. The work [42] indicates the pulse width ratios are derived from the reference curve for the PWM. During the pre-delivery test, we can change the wind between cut-in and cut-out speed in different modes such as steady speed, random wind, ad step wind. Then, MPR of all wind modes can be recorded. So $T_{S}$ can be chosen according to MPR.

(B) The Calculation of Fault Detection Time

If an OSF occurs, the fault show time as analyzed in Section 2.3.1 would appear. Once the fault occurs at the beginning of the fault blank time, the detection time is the longest. It has to wait more than half of the current fundamental period for the fault show time.

Let us suppose the fault occurs at $t_{0}$. The period of the fault blank time $T_{x}$ and $T_{S}$ are not proportional as seen in Equation (16).

$$
T_{x}=n * T_{s}+\varepsilon
$$

where $\varepsilon<T_{s} ; n$ is a positive integer. Therefore, assuming $T_{c}$ as the telecommunication and calculation time, the detection time $T$ is equal to the longest one $T_{\max }$ as seen in Figure 9a.

$$
\begin{gathered}
T=T_{\max }=(n+2) T_{s}+T_{\mathcal{C}} \\
T=T_{\min }=T_{s}+T_{\mathcal{c}}
\end{gathered}
$$




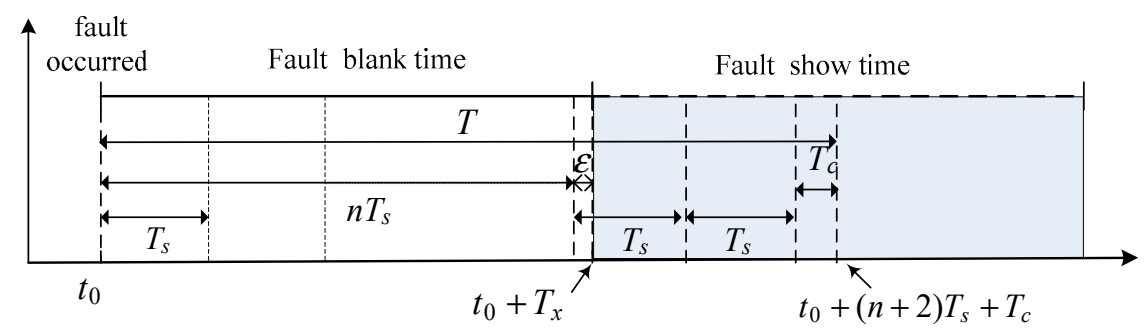

(a) the maximum detection time

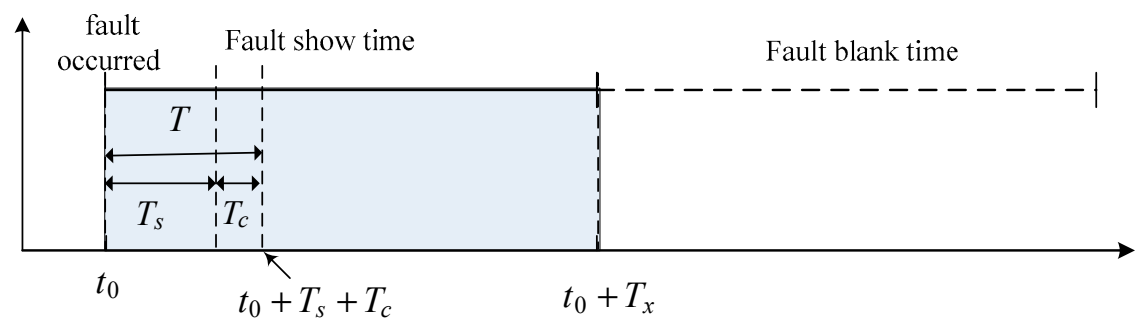

(b) the minimum detection time

Figure 9. fault detection time: (a) The maximum detection time and (b) the minimum detection time.

If the fault occurs at the beginning of the fault show time, the detection time is the shortest one $T_{\min }$. Assuming the fault occurred at $t_{0}$, the detection time $T$ as seen in Figure $9 \mathrm{~b}$ shown can be expressed.

In conclusion, the values of detection time are less than one current fundamental period. In addition, the shortest detection time is nearly equal to the sampling time.

\subsection{Measurement of Electrical Signal}

The key of the fault diagnosis algorithm is the measurement process. Its principle is shown in Figure 10, which we also realize in the next simulation part. In this process, the special RMS voltage $U_{k N}$ is calculated. Before the calculation of $U_{k N}$, the period $T_{s}$ should be obtained after the pulse width measurement. The detail expatiation about $T_{S}$ is listed in Section 2.2.

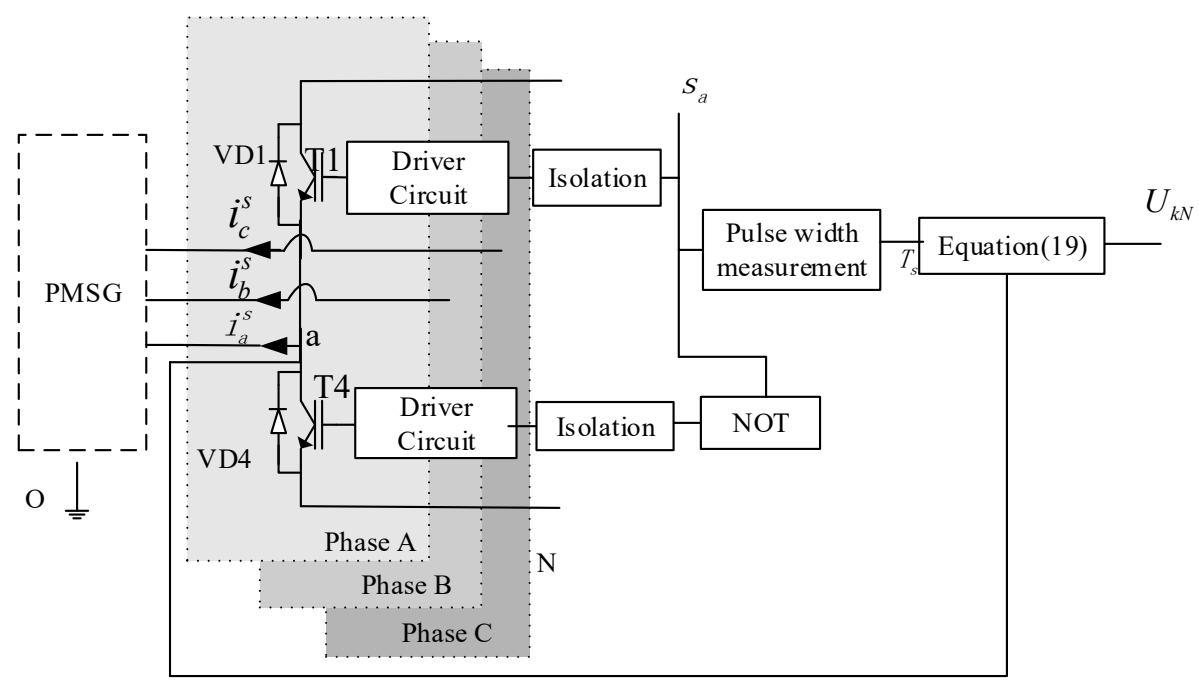

Figure 10. The measurement diagram of the electrical signal.

The calculation of $U_{k N}$ is shown below.

$$
U_{k N}=\sqrt{\frac{\int_{t-T_{s}}^{t}\left[u_{k N}(t)\right]^{2} d t}{T_{s}}}
$$


Assume $T_{S}$ is proper and take T1 fault as an example. If the measurement is conducted during the positive cycle of faulty current. $U_{a N}$ are equal to 0 due to $u_{a N}=0$ according to Table 3 . Once faulty current turns to a negative cycle, $U_{k N}$ can be expressed by Equation (20) below.

$$
U_{a N}=\sqrt{\frac{\int_{t-T_{s}}^{t}\left[s_{a} u_{d c}\right]^{2} d t}{T_{s}}}
$$

$U_{a N}$ are unequal to 0 . In addition, when faulty current is under the zero-crossing section, $u_{a N}$ may be not equal to 0 as $U_{a N}$. That means only when the fault show time comes out, $U_{k N}$ is 0 .

\section{Simulation and Experimental Results}

The model of PMSGWS as illustrated in Figure 6 is built on the basis of the PSCAD environment. The main system parameters of PMSG for simulation are given in Tables 1 and 2 . The parameters are set the same as expressed in Section 2.2.2. Figure 4 gives the photos of experiment devices. Dynamic responses of voltage are shown in this section. Figure 11 is the experimental responses of the lower tube voltage. The results of the simulations are illustrated by Figures 12 and 13.

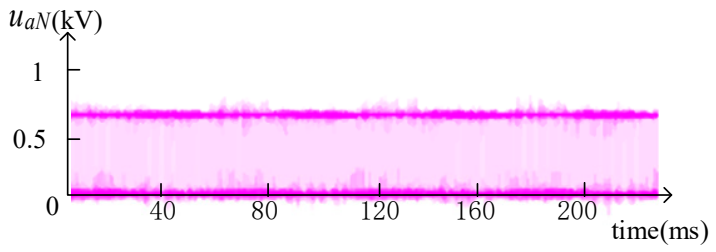

(a)

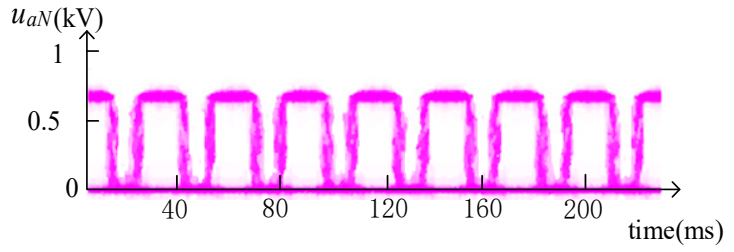

(b)

Figure 11. Experimental results: (a) The normal operating condition; (b) the OSF from T1.

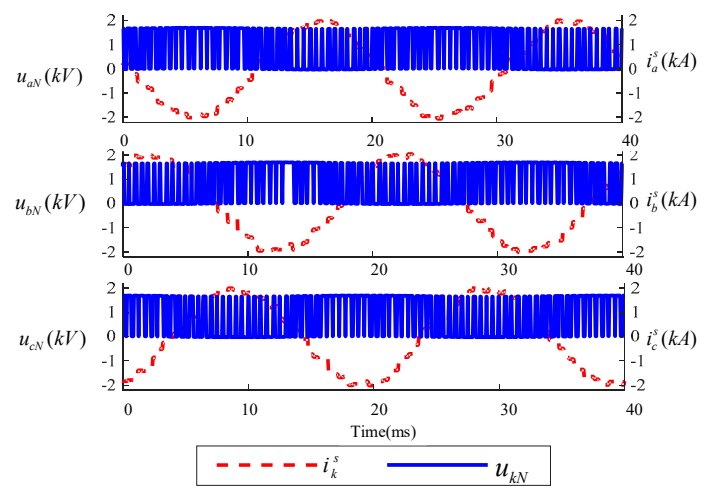

(a)

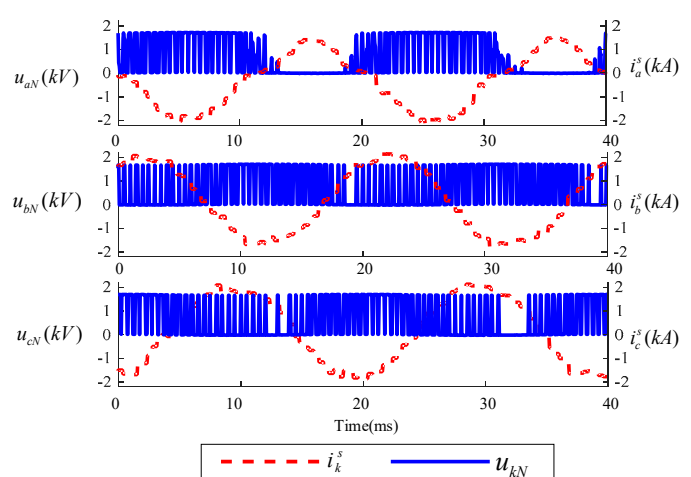

(b)

Figure 12. Simulation results regarding the time-domain waveforms of the lower tube voltage in MSC:

(a) The normal operating condition; (b) the open-circuit fault from T1.

Comparing Figure 11a with Figure 11b, it is visible that, under different operating conditions, although the similar feature that all $u_{a N}$ skip on 0 and $0.65 \mathrm{Kv}$ is revealed in the fault blank time, different characteristics of $u_{a N}$ are shown during the fault show time.

We also assume T1 and T4 are the top and lower switch of MSC in phase A, respectively. Figures 12 and 13 present the simulation results during $\mathrm{T} 1$ fault occurrence with an imposed reference wind speed of $10.5 \mathrm{~m} / \mathrm{s}$. The time-domain waveforms of lower tube voltage are similar to that obtained by experiments. $u_{a N}$ change with the fault show time when OSF occurs in T1. During $i_{a}^{s}=0, u_{a N}$ shows different features in comparison with that during $i_{a}^{s} \neq 0$. Comparing Figure 12 with Figure 11, it is 
visible that $u_{k 0}$ is more complex than $u_{k N}$. There are several values of $u_{k 0} . u_{a 0}$ is smaller than 0 during $i_{a}^{s}>0$.
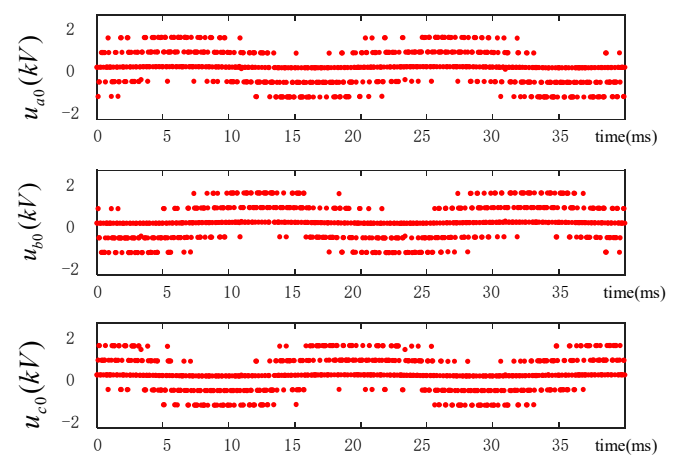

(a)
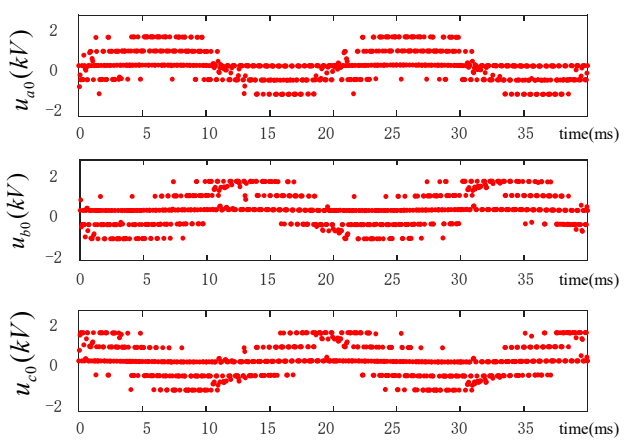

(b)

Figure 13. Simulation results regarding the time-domain waveforms of the stator voltage in MSC: (a) The normal operating condition; (b) the open-circuit fault from T1.

These simulation results indicate a similar phenomenon as obtained by experiments. In details, $u_{a N}$ does not skip on 0 and $1.5 \mathrm{Kv}$ during the fault show time. $u_{k 0}$ is more complex than $u_{k N}$. As shown in Figure 13, $u_{k 0}$ with a high frequency are discrete most of the time. During the zero-crossing section, $u_{k 0}$ obtains some values not as the non-zero-crossing section. The responses in Figures 12 and 13 are consistent with experiments as well as analyses in Section 1.

The effectivity and availability of the simulation model are verified according to the above analysis of faulty behaviors. Considering the damage to devices, we test the diagnosis method in simulation surroundings. Six cases including the normal condition with $7 \mathrm{~m} / \mathrm{s}$, the normal condition with $10.5 \mathrm{~m} / \mathrm{s}$, OSF in T1 with $7 \mathrm{~m} / \mathrm{s}$, OSF in T4 with $7 \mathrm{~m} / \mathrm{s}$, OSF in T1 with $10.5 \mathrm{~m} / \mathrm{s}$, and OSF in T4 with $10.5 \mathrm{~m} / \mathrm{s}$ are demonstrated for verifying the performance of the proposed method. All faults occur at the $0.02 \mathrm{st}$ second. Setting sample time as a $0.003 \mathrm{~s}$, we can obtain the values of $U_{a}$.

These values of localization variables in Figure 14 can be obviously categorized into three main types: normal case between 0 and $1, \mathrm{~T} 1$ fault case reducing to 0 , and $\mathrm{T} 4$ fault case up to 1 . The OSF in T4 with $7 \mathrm{~m} / \mathrm{s}$ is detected in the shortest time of about $0.003 \mathrm{~s}$. The longest detection time is about $0.015 \mathrm{~s}$ showing in the event of $\mathrm{T} 1$ fault with $7 \mathrm{~m} / \mathrm{s}$. These responses prove that the proposed diagnosis algorithm with a certain period can distinguish a faulty switch in different wind speeds. It also proves that the proposed diagnosis algorithm can achieve fault detection in this paper.

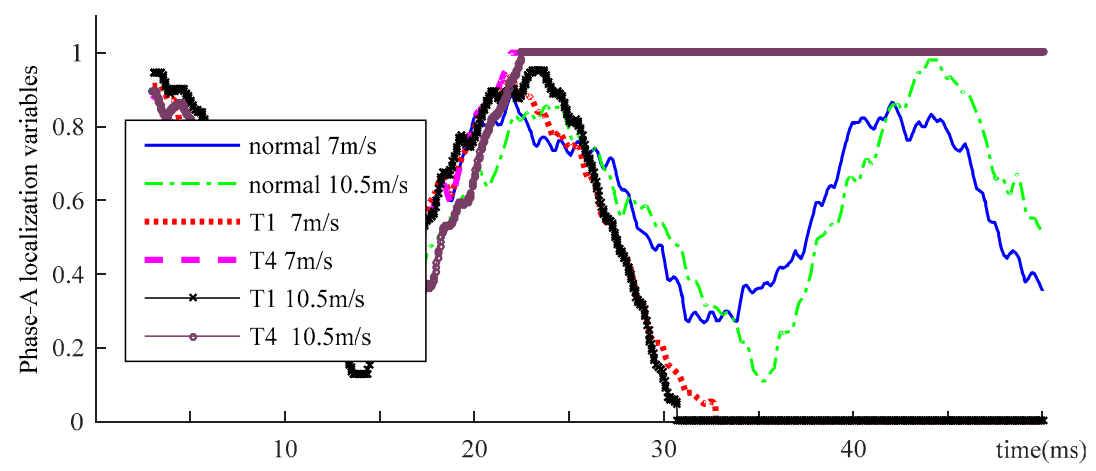

Figure 14. Phase-A location variables at different cases.

Moreover, we also take these results to compare with other previous methods, as presented in Table 5. The proposed method with similar detection speed as that in Reference [18] even though 
the faulty current in Reference [18] is considered as a unidirectional one. Absolutely, the robust and accuracy proven by the results can meet the requirements of grid stability.

Table 5. The comparison between the proposed method and already existing method.

\begin{tabular}{ccccc}
\hline Diagnostic Methods & The Object & $\begin{array}{c}\text { The Complex of } \\
\text { Background }\end{array}$ & Faulty Current & Threshold Setting \\
\hline $\begin{array}{c}\text { Current-changing trend } \\
\text { detection method [34] }\end{array}$ & $\begin{array}{c}\text { The PWM voltage } \\
\text { source rectifier }\end{array}$ & bilateral & need \\
\hline The normalized way [18] & $\begin{array}{c}\text { Power inverter in } \\
\text { electric vehicles }\end{array}$ & unidirectional & need \\
\hline $\begin{array}{c}\text { The zero-crossing } \\
\text { feature-based method [33] }\end{array}$ & $\begin{array}{c}\text { banverters using } \\
\text { the NPC topology }\end{array}$ & bilateral & need \\
\hline Proposed method & MSC of PMSGWS & bilateral & unnecessary \\
\hline
\end{tabular}

\section{Conclusions}

In order to handle unforeseen faults and to achieve high reliability levels with the wind conversion chain, the fault detection and identification are becoming more and more important for industrial applications. In this paper, the analysis under arm current flowing or cutting off enhances the knowledge of faulty behaviors and works on finding the criteria to detect faulty switches. Then, a simple diagnostic method for OSF in MSC of a PMSG drive for wind turbine application is proposed. The fault diagnosis process without threshold settings is one of the main advantages of this method. Simulation and experimental results confirm the validity of the new proposed fault detection method.

The full analysis of faulty behaviors in this paper pay as a key for diagnosis, fault tolerance, and optimized control in future research. Due to the merit without thresholds, the proposed method may be extended to a wider application. In further research, we will use these obtained principles as the base. An engineering implementation is also a future goal.

Author Contributions: For this paper, all authors have participated in corresponding researches. Z.H. conceived and designed the proposed algorithm; Z.Y. and Z.H. conceived and performed the experiments; Z.H. analyzed the data; Z.H. wrote the paper. T.Y. and Z.Y. revised the English writing of this paper. The supervision, project administration, and the funding acquisition are supported by T.Y. All authors gave advice for the manuscript.

Funding: This work was supported by National Natural Science Foundation of China No. 61102039 and No. 51577046. 973 plan No. 2012CB215106, Science, Technology Planning Project of Hunan Province No. 14JJ7029, and Project supported by Open Foundation of first level zhejiang key in key discipline of Control Science and Engineering.

Conflicts of Interest: The authors declare no conflict of interest.

\section{Nomenclature}

$e_{k s} \quad$ back trapezoidal EMFs of generator $(\mathrm{kV})$

$R_{k s} \quad$ phase stator resistance ()

$L_{k s} \quad$ phase stator inductance $(\mathrm{mH})$

$i_{k}^{s} \quad$ stator current $(\mathrm{kA})$

$u_{\text {No }} \quad \mathrm{N}$ to neutral voltage $(\mathrm{kV})$

$s_{k} \quad$ gate command signals

$u_{k N} \quad$ lower tube voltage $(\mathrm{kV})$

$U_{k N} \quad$ special RMS voltage $(\mathrm{kV})$

$T_{x} \quad$ the fault blank period (ms)

$T_{S} \quad$ the sampling period (ms)

$U_{\text {dcref }} \quad$ DC-Link reference voltage $(\mathrm{kV})$ 
$T_{c} \quad$ the telecommunication and calculation time (ms)

$T \quad$ detection time (ms)

$\omega \quad$ the actual rotor speed $(\mathrm{rad} / \mathrm{s})$

$u_{r k} \quad$ PWM control signals

$U_{k} \quad$ fault localization variables

\section{References}

1. Sawczuk, W. The Application of Vibration Accelerations in the Assessment of Average Friction Coefficient of a Railway Brake Disc. Meas. Sci. Rev. 2017, 17, 125-134. [CrossRef]

2. Sawczuk, W. Appliation of Vibroacoustic Dlagnostics to Evaluation of Wear of Friction Pads Rail Brake Disc. Eksploat. I Niezawodn.-Maint. Reliab. 2016, 18, 565-571. [CrossRef]

3. Glowacz, A.; Glowacz, W.; Glowacz, Z.; Kozik, J.; Gutten, M.; Korenciak, D.; Khan, Z.F.; Irfan, M.; Carletti, E. Fault Dlagnosis of Three Phase Induction Motor Using-Current Singnal, MSAF-Ratio15 and Selected Classifiers. Arch. Metall. Mater. 2017, 62, 2413-2419. [CrossRef]

4. Beainy, A.; Maatouk, C.; Moubayed, N.; Kaddah, F. Decision on Failure Diagnosis and Condition Monitoring technique for Wind Conversion System. In Proceedings of the IECON 2015-41st Annual Conference of the IEEE, Yokohama, Japan, 9-12 November 2015; pp. 5148-5155. [CrossRef]

5. Choi, U.M.; Blaabjerg, F.; Lee, K.B. Study and Handling Methods of Power IGBT Module Failures in Power Electronic Converter Systems. IEEE Trans. Power Electron. 2015, 30, 2517-2533. [CrossRef]

6. Rivera-Guillen, J.R.; De Santiago-Perez, J.J.; Amezquita-Sanchez, J.P.; Valtierra-Rodriguez, M.; Romero-Troncoso, R.J. Enhanced FFT-based Method for Incipient Broken Rotor Bar Detection In Induction Motors During the Startup Transient. Measurement 2018, 124, 277-285. [CrossRef]

7. Singh, G.; Naikan, V.N.A. Detection of Half Broken Rotor Bar Fault In VFD Driven Induction Motor Drive Using Motor Square Current MUSIC Analysis. Mech. Syst. Signal Process. 2018, 110, 333-348. [CrossRef]

8. Michalak, M.; Sikora, B.; Sobczyk, J. Diagnostic Model for Longwall Conveyor Engines; Book Series: Advances in Intelligent Systems and Computing; Springer International Publishing: Katowice, Poland, 2016; Volume 391, pp. 437-448.

9. Igba, J.; Alemzadeh, K.; Durugbo, C.; Eiriksson, E.T. Analysing RMS and Peak Values of Vibration Signals for Condition Monitoring of Wind Turbine Gearboxes. Renew. Energy 2016, 91, 90-106. [CrossRef]

10. Rokicki, E.; Szczepanik, R.; Rzadkowski, R.; Jarosław Spychała, R.S.; Drewczyński, M. Analysis of Middle Bearing Failure in Rotor Jet Engine Using Tip-Timing and RMS Technique. J. Vib. Eng. Technol. 2014, 4, 31-36. [CrossRef]

11. Corne, B.; Vervisch, B.; Derammelaere, S.; Knockaert, J.; Desmet, J. The Reflection of Evolving Bearing Faults In the Stator Current's Extended Park Vector Approach for Induction machines. Mech. Syst. Signal Process. 2018, 107, 168-182. [CrossRef]

12. Riera-Guasp, M.; Antonino-Daviu, J.A.; Capolino, G.-A. Advances in Electrical Machine, Power Electronic, and Drive Condition Monitoring and Fault Detection: State of the Art. IEEE Trans. Ind. Electron. 2015, 62, 1746-1759. [CrossRef]

13. Gao, Z.; Ding, S.X. A Survey of Fault Diagnosis and Fault-Tolerant Techniques Part I: Fault Diagnosis with Model-Based and Signal-Based Approaches. IEEE Trans. Ind. Electron. 2015, 62, 3757-3767. [CrossRef]

14. Hang, J.; Zhang, J.; Cheng, M.; Ding, S. Detection and Discrimination of Open-Phase Fault in Permanent Magnet Synchronous Motor Drive System. IEEE Trans. Power Electron. 2016, 31, 4697-4709. [CrossRef]

15. Yang, Z.; Chai, Y. A Survey of Fault Diagnosis for Onshore Grid-Connected Converterin Wind Energy Conversion Systems. Renew. Sustain. Energy Rev. 2016, 66, 345-359. [CrossRef]

16. Kamel, T.; Biletskiy, Y.; Chang, L. Fault Diagnoses for Industrial Grid-Connected Converters in the Power Distribution Systems. IEEE Trans. Ind. Electron. 2015, 62, 6496-6507. [CrossRef]

17. Moeini, R.; Tricoli, P.; Hemida, H.; Baniotopoulos, C. Increasing the reliability of wind turbines using condition monitoring of semiconductor devices: A review. IET Renew. Power Gener. 2018, 12, 182-189. [CrossRef]

18. Wei, H.; Zhang, Y.; Yu, L.; Zhang, M.; Teffah, K. A New Diagnostic Algorithm for Multiple IGBTs Open Circuit Faults by the Phase Currents for Power Inverter in Electric Vehicles. Energies 2018, 11, 1508. [CrossRef] 
19. Zidani, F.; Diallo, D.; Benbouzid, M.E.H.; Nait-Said, R. A fuzzy-based approach for the diagnosis of fault modes in a voltage-fed PWM inverter induction motor drive. IEEE Trans. Ind. Electron. 2008, 55, 586-596. [CrossRef]

20. An, Q.-T.; Sun, L.; Sun, L.-Z. Current Residual Vector-Based Open-Switch Fault Diagnosis of Inverters in PMSM Drive Systems. IEEE Trans. Power Electron. 2015, 30, 2814-2828. [CrossRef]

21. Trabelsi, M.; Semail, E.; Nguyen, N.K. Experimental Investigation of Inverter Open-Circuit Fault Diagnosis for Biharmonic Five-Phase Permanent Magnet Drive. IEEE J. Emerg. Sel. Top. Power Electron. 2018, 6, 339-352. [CrossRef]

22. Nuno, M.A.F.; Jorge, O.E.; António, J.M.C. A New Approach for Current Sensor Fault Diagnosis in PMSG Drives for Wind Energy Conversion Systems. IEEE Trans. Ind. Appl. 2014, 50, 1206-1214. [CrossRef]

23. Trabelsi, M.; Boussak, M.; Benbouzid, M. Multiple criteria for high performance real-time diagnostic of single and multiple open-switch faults in AC-motor drives: Application to IGBT-based voltage source inverter. Electr. Power Syst. Res. 2017, 144, 136-149. [CrossRef]

24. Gao, Z.; Cecati, C.; Ding, S.X. A Survey of Fault Diagnosis and Fault-Tolerant Techniques-Part II: Fault Diagnosis With Knowledge-Based and Hybrid/Active Approaches. IEEE Trans. Ind. Electron. 2015, 62, 3768-3774. [CrossRef]

25. Cai, B.; Zhao, Y.; Liu, H. A Data-Driven Fault Diagnosis Methodology in Three-Phase Inverters for PMSM Drive Systems. IEEE Trans. Power Electron. 2017, 32, 5590-5600. [CrossRef]

26. Yang, S.; Chen, G.; Jian, D. On-line Stator Open-Phase Fault Detection and Tolerant Control for Permanent Magnet Machines using the Neutral Point Voltage. IEEE Access 2017, 5, 1076-1082. [CrossRef]

27. Wang, T.; Qi, J.; Xu, H.; Wang, Y.; Liu, L.; Gao, D. Fault Diagnosis Method Based on FFT-RPCA-SVM for Cascaded-Multilevel Inverter. ISA Trans. 2016, 60, 156-163. [CrossRef] [PubMed]

28. Huang, Z.; Wang, Z.; Zhang, H. Multiple Open-Circuit Fault Diagnosis Based on Multistate Data Processing and Subsection Fluctuation Analysis for Photovoltaic Inverter. IEEE Trans. Instrum. Meas. 2018, 67, 516-527. [CrossRef]

29. Rekha, S.N.; Jeyanthy, P.A.; Devaraj, D. Wavelet Transform Based Open Circuit Fault Diagnosis in the Converter Used in Wind Energy Systems. In Proceedings of the Name of the 2017 IEEE International Conference on Intelligent Techniques in Control, Srivilliputhur, India, 23-25 March 2017. [CrossRef]

30. Jlassi, I.; Cardoso, A.J.M. IGBTs and Current Sensors Fault Diagnosis in Direct-Drive PSMG Wind Turbine Systems using Adaptive Thresholds. In Proceedings of the 43rd Annual Conference of the IEEE Industrial Electronics Society, Beijing, China, 29 October-1 November 2017. [CrossRef]

31. Cheng, S.; Chen, Y.-T.; Yu, T.-J.; Wu, X. A Novel Diagnostic Technique for Open-Circuited Faults of Inverters Based on Output Line-To-Line Voltage Model. IEEE Trans. Ind. Electron. 2016, 63, 4412-4421. [CrossRef]

32. Wang, T.; Xu, H.; Han, J.; Elbouchikhi, E.; Benbouzid, M.E.H. Cascaded H-bridge multilevel inverter system fault diagnosis using a PCA and multi-class relevance vector machine approach. IEEE Trans. Power Electron. 2015, 30, 7006-7018. [CrossRef]

33. Gou, B.; Ge, X.; Wang, S.; Feng, X.; Kuo, J.B.; Habetler, T.G. An Open-Switch Fault Diagnosis Method for Single-Phase PWM Rectifier Using a Model-Based Approach in High-Speed Railway Electrical Traction Drive System. IEEE Trans. Power Electron. 2016, 31, 3816-3826. [CrossRef]

34. Jlassi, I.; Estima, J.O.; Khil, S.K.E.; Bellaaj, N.M.; Cardoso, A.J.M. A Robust Observer-Based Method for IGBTs and Current Sensors Fault Diagnosis in Voltage-Source Inverters of PMSM Drives. IEEE Trans. Ind. Appl. 2017, 53, 2894-2905. [CrossRef]

35. Jlassi, I.; Estima, J.O.; Khil, S.K.E.; Bellaaj, N.M.; Cardoso, A.J.M. Multiple Open-Circuit Faults Diagnosis in Back-to-Back Converters of PMSG Drives for Wind Turbine Systems. IEEE Trans. Power Electron. 2015, 30, 2689-2703. [CrossRef]

36. Lee, J.S.; Lee, K.B.; Blaabjerg, F. Open-Switch Fault Detection Method of a Back-To-Back Converter Using NPC Topology for Wind Turbine Systems. IEEE Trans. Ind. Appl. 2015, 51, 325-335. [CrossRef]

37. Shi, T.; He, Y.; Deng, F.; Tong, J.; Wang, T.; Shi, L. Online Diagnostic Method of Open-Wwitch Faults in PWM Voltage Source Rectifier Based on Instantaneous AC Current Distortion. IET Electr. Power Appl. 2018, 12, 447-454. [CrossRef]

38. Li, W.; Li, L.; Gao, H.; Li, D.; Zhang, X.; Fan, Y. Influence of Direct-Connected Inverter with One Power Switch Open Circuit Fault on Electromagnetic Field and Temperature Field of Permanent Magnet Synchronous Motor. IET Electr. Power Appl. 2018, 12, 815-825. [CrossRef] 
39. Haghnazari, S.; Khodabandeh, M.; Zolghadri, M.R. Fast fault detection method for modular multilevel converter semiconductor power switches. IET Power Electron. 2016, 9, 165-174. [CrossRef]

40. Masrur, M.A. Assumption or fact?-Line-to-neutral voltage expression in an unbalanced 3-phase circuit during inverter switching. IEEE Trans. Educ. 2009, 52, 222-227. [CrossRef]

41. Yang, M.; Lang, X.; Long, J.; Xu, D. A Flux Immunity Robust Predictive Current Control with Incremental Model and Extended State Observer for PMSM Drive. IEEE Trans. Power Electron. 2017, 32, 9267-9279. [CrossRef]

42. Broeck, H.W.V.D.; Skudelny, H.-C. Analysis and Realization of a Pulsewidth Modulator Based on Voltage Space Vectors. IEEE Trans. Ind. Appl. 1988, 24, 142-150. [CrossRef]

(C) 2018 by the authors. Licensee MDPI, Basel, Switzerland. This article is an open access article distributed under the terms and conditions of the Creative Commons Attribution (CC BY) license (http://creativecommons.org/licenses/by/4.0/). 